\title{
Cardigan Welsh Corgi
}

National Cancer Institute

\section{Source}

National Cancer Institute. Cardigan Welsh Corgi. NCI Thesaurus. Code C53751.

The Cardigan Welsh Corgi is a long, low dog with very large erect ears, a broad flat skull, and a long, low-set tail. It tends to be a heavier than the Pembroke Welsh Corgi. Its double coat has a harsh medium length outer coat lined with a soft, dense undercoat. Colors are brindle, blue merle, black, black and tan, black and brindle, sable, and red, often with white markings. Height: 10-13 inches (25-33 cm.) Weight: $25-30$ pounds (11-14 kg.) 